Original Article

\title{
Spanish Video-Assisted Thoracic Surgery Group: Method, Auditing, and Initial Results From a National Prospective Cohort of Patients Receiving Anatomical Lung Resections
}

\section{Raul Embun ${ }^{a, *}$, Iñigo Royo-Crespo ${ }^{a}$, José Luis Recuero Díaz ${ }^{a}$, Sergio Bolufer ${ }^{b}$, Sergi Call ${ }^{c}$,} Miguel Congregado $^{\mathrm{d}}$, David Gómez-de Antonio ${ }^{\mathrm{e}}$, Marcelo F. Jimenez ${ }^{\mathrm{f}}$, Nicolas Moreno-Mata ${ }^{\mathrm{g}}$, Borja Aguinagalde $^{\mathrm{h}}$, Sergio Amor-Alonso ${ }^{\mathrm{i}}$, Miguel Jesús Arrarás ${ }^{j}$, Ana Isabel Blanco Orozco ${ }^{\mathrm{k}}$, Marc Boada ${ }^{l}$, Alberto Cabañero Sánchez ${ }^{\mathrm{g}}$, Isabel Cal Vázquez ${ }^{\mathrm{m}}$, Ángel Cilleruelo Ramos ${ }^{\mathrm{n}}$, Silvana Crowley Carrasco ${ }^{e}$, Elena Fernández-Martín ${ }^{\tilde{}}$, Santiago García-Barajas ${ }^{\circ}$, Maria Dolores García-Jiménez $^{\mathrm{p}}$, Jose María García-Prim ${ }^{\mathrm{q}}$, Jose Alberto Garcia-Salcedo ${ }^{\mathrm{r}}$, Juan José Gelbenzu-Zazpes ${ }^{\mathrm{s}}$, Carlos Fernando Giraldo-Ospinat ${ }^{\mathrm{t}}$, María Teresa Gómez Hernández ${ }^{\mathrm{f}}$, Jorge Hernández ${ }^{\mathrm{u}}$, Jennifer D. Illana Wolf ${ }^{\mathrm{v}}$, Alberto Jauregui Abularach ${ }^{\mathrm{w}}$, Unai Jiménez ${ }^{\mathrm{x}}$, Iker López Sanz ${ }^{\mathrm{h}}$, Néstor J. Martínez-Hernández ${ }^{\mathrm{y}}$, Elisabeth Martínez-Téllez ${ }^{\mathrm{z}}$, Lucía Milla Collado ${ }^{\text {aa }}$, Roberto Mongil Poce ${ }^{t}$, Francisco Javier Moradiellos-Díez ${ }^{i}$, Ramón Moreno-Balsalobre ${ }^{m}$, Sergio B. Moreno Merino ${ }^{\mathrm{d}}$, Carme Obiols ${ }^{c}$, Florencio Quero-Valenzuela ${ }^{\mathrm{ab}}$, María Elena Ramírez-Gil ${ }^{\mathrm{s}}$,

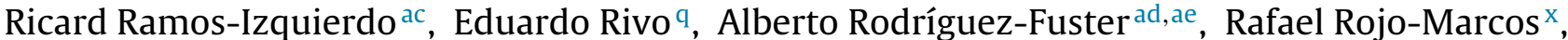
David Sanchez-Lorente ${ }^{1}$, Laura Sanchez Moreno ${ }^{\text {af }}$, Carlos Simón ${ }^{\mathrm{ag}}$, Juan Carlos Trujillo-Reyes ${ }^{\mathrm{z}}$, Florentino Hernando Trancho ${ }^{\tilde{n}}$

\footnotetext{
a Servicio de Cirugía Torácica, Hospital Universitario Miguel Servet y Hospital Clínico Universitario Lozano Blesa, IIS Aragón, Zaragoza, Spain

b Servicio de Cirugía Torácica, Hospital General Universitario de Alicante, Alicante, Spain

' Servicio de Cirugía Torácica, Hospital Universitari Mútua Terrasa, Universidad de Barcelona, Terrasa, Barcelona, Spain

d Servicio de Cirugía Torácica, Hospital Universitario Virgen Macarena, Sevilla, Spain

e Servicio de Cirugía Torácica, Hospital Universitario Puerta de Hierro Majadahonda, Madrid, Spain

f Servicio de Cirugía Torácica, Hospital Universitario de Salamanca, Universidad de Salamanca, IBSAL, Salamanca, Spain

g Servicio de Cirugía Torácica, Hospital Universitario Ramón y Cajal, Madrid, Spain

h Servicio de Cirugía Torácica, Hospital Universitario de Donostia, San Sebastián-Donostia, Spain

i Servicio de Cirugía Torácica, Hospital Universitario Quironsalud Madrid, Madrid, Spain

j Servicio de Cirugía Torácica, Fundación Instituto Valenciano de Oncología, Valencia, Spain

k Servicio de Cirugía Torácica, Hospital Universitario Virgen del Rocío, Sevilla, Spain

${ }^{1}$ Servicio de Cirugía Torácica, Hospital Clinic de Barcelona, Instituto Respiratorio, Universidad de Barcelona, Barcelona, Spain

m Servicio de Cirugía Torácica, Hospital Universitario La Princesa, Madrid, Spain

n Servicio de Cirugía Torácica, Hospital Clínico Universitario, Valladolid, Spain

ñ Servicio de Cirugía Torácica, Hospital Clínico San Carlos, Madrid, Spain

- Servicio de Cirugía Torácica, Hospital Universitario de Badajoz, Badajoz, Spain

P Servicio de Cirugía Torácica, Hospital Universitario de Albacete, Albacete, Spain

" Servicio de Cirugía Torácica, Hospital Universitario Santiago de Compostela, Santiago de Compostela, Spain

${ }^{\mathrm{r}}$ Servicio de Cirugía Torácica, Hospital Universitario 12 de Octubre, Madrid, Spain

s Servicio de Cirugía Torácica, Complejo Hospitalario de Navarra, Pamplona, Spain

t Servicio de Cirugía Torácica, Hospital Regional Universitario, Málaga, Spain

" Servicio de Cirugía Torácica, Hospital Universitario Sagrat Cor, Barcelona, Spain

v Servicio de Cirugía Torácica, Hospital Puerta del Mar, Cádiz, Spain

w Servicio de Cirugía Torácica, Hospital Universitario Vall d'Hebron, Barcelona, Spain

x Servicio de Cirugía Torácica, Hospital Universitario Cruces, Bilbao, Spain

y Servicio de Cirugía Torácica, Hospital Universitario La Ribera, Alcira, Valencia, Spain

z Servicio de Cirugía Torácica, Hospital Santa Creu y Sant Pau, Universidad Autónoma de Barcelona, Barcelona, Spain

aa Servicio de Cirugía Torácica, Hospital Arnau de Vilanova, Lleida, Spain

ab Servicio de Cirugía Torácica, Hospital Virgen de las Nieves, Granada, Spain

ac Servicio de Cirugía Torácica, Hospital Universitario de Bellvitge, Hospitalet de Llobregat, Barcelona, Spain

ad Servicio de Cirugía Torácica, Hospital del Mar, Barcelona, Spain

ae IMIM (Instituto de Investigación Médica Hospital del Mar), Barcelona, Spain

* Corresponding author.

E-mail address: raulembun@gmail.com (R. Embun).
} 
af Servicio de Cirugía Torácica, Hospital Universitario Marqués de Valdecilla, Santader, Spain

ag Servicio de Cirugía Torácica, Hospital Universitario Gregorio Marañón, Madrid, Spain

\section{A R T I C L E I N F O}

\section{Article history:}

Received 31 October 2019

Accepted 5 January 2020

Available online xxx

\section{Keywords:}

Video-assisted thoracic surgery

VATS

Lung cancer

Lobectomy

Audit

Multicentre study

\section{A B S T R A C T}

Introduction: Our study sought to know the current implementation of video-assisted thoracoscopic surgery (VATS) for anatomical lung resections in Spain. We present our initial results and describe the auditing systems developed by the Spanish VATS Group (GEVATS).

Methods: We conducted a prospective multicentre cohort study that included patients receiving anatomical lung resections between $12 / 20 / 2016$ and 03/20/2018. The main quality controls consisted of determining the recruitment rate of each centre and the accuracy of the perioperative data collected based on six key variables. The implications of a low recruitment rate were analysed for "90-day mortality" and "Grade IIIb-V complications".

Results: The series was composed of 3533 cases (1917 VATS; 54.3\%) across 33 departments. The centres' median recruitment rate was 99\% (25-75th:76-100\%), with an overall recruitment rate of $83 \%$ and a data accuracy of $98 \%$. We were unable to demonstrate a significant association between the recruitment rate and the risk of morbidity/mortality, but a trend was found in the unadjusted analysis for those centres with recruitment rates lower than $80 \%$ (centres with $95-100 \%$ rates as reference): grade IIIb-V OR $=0.61$ ( $p=0.081)$, 90-day mortality $\mathrm{OR}=0.46(p=0.051)$.

Conclusions: More than half of the anatomical lung resections in Spain are performed via VATS. According to our results, the centre's recruitment rate and its potential implications due to selection bias, should deserve further attention by the main voluntary multicentre studies of our speciality. The high representativeness as well as the reliability of the GEVATS data constitute a fundamental point of departure for this nationwide cohort.

(C) 2020 SEPAR. Published by Elsevier España, S.L.U. All rights reserved.

\section{Grupo español de cirugía torácica asistida por videoimagen: método, auditoría y resultados iniciales de una cohorte nacional prospectiva de pacientes tratados con resecciones anatómicas del pulmón}

\section{R E S U M E N}

Introducción: Nuestro estudio buscó conocer el grado de implementación actual de la cirugía toracoscópica asistida por video (VATS, por sus siglas en inglés) para las resecciones pulmonares anatómicas en España. Presentamos nuestros resultados iniciales y describimos los sistemas de auditoría desarrollados por el grupo español de VATS (GEVATS).

Métodos: Realizamos un estudio de cohortes prospectivo multicéntrico que incluyó pacientes que fueron tratados con resecciones pulmonares anatómicas entre el 20/12/2016 y el 20/03/2018. Los controles de calidad principales consistieron en determinar la tasa de reclutamiento de cada centro y la precisión de los datos perioperatorios recolectados en base a seis variables clave. Se analizaron las implicaciones de una baja tasa de reclutamiento para "mortalidad a los 90 días" y "complicaciones de grado IIIb-V". Resultados: La serie estaba compuesta por 3533 casos (1917 VATS; 54,3\%) en 33 servicios. La mediana de la tasa de reclutamiento de los centros fue del 99\% (p25-p75: 76-100\%), con una tasa de reclutamiento global del $83 \%$ y una precisión de los datos del $98 \%$. No pudimos demostrar una asociación significativa entre la tasa de reclutamiento y el riesgo de morbi-mortalidad, pero se encontró una tendencia en el análisis no ajustado para aquellos centros con tasas de reclutamiento inferiores al 80\% (usando los centros con tasas de $95-100 \%$ como referencia): $O R=0,61$ para el grado IIIb-V $(p=0,081), O R=0,46$ para la mortalidad a los 90 días $(p=0,051)$.

Conclusiones: Más de la mitad de las resecciones pulmonares anatómicas en España se realizan a través de VATS. Según nuestros resultados, la tasa de reclutamiento del centro y sus posibles implicaciones debido al sesgo de selección, deberían recibir más atención por parte de los principales estudios multicéntricos voluntarios de nuestra especialidad. La alta representatividad y la confiabilidad de los datos de GEVATS constituyen un punto de partida fundamental para esta cohorte nacional.

(C) 2020 SEPAR. Publicado por Elsevier España, S.L.U. Todos los derechos reservados.

\section{Introduction}

Because of improvements in the computerisation, management, and exploitation of clinical data systems, an increasing number of thoracic surgery studies have been derived from population databases or large multicentre registries. In this sense, the classic paradigm of a limited and often insufficient number of patients is being replaced by the greater need to examine the quality and reliability of our data. ${ }^{1}$ Even within our specialty, the number of studies attempting to analyse and publicise the quality of their recorded data has become exceptional.

Currently, a significant disparity exists regarding the implementation of video-assisted thoracoscopic surgery (VATS) applied to anatomical lung resections at the population level. ${ }^{2,3}$ In our country, the most recent reference to the implementation of this surgical technique is included in the survey promoted by the Spanish Society of Thoracic Surgery (SECT). ${ }^{4}$

Despite the extensive literature concluding that VATS is associated with a lower rate of postoperative complications compared 
with open surgery, the conclusions concerning the effect of the approach on postoperative mortality are uncertain, with major meta-analyses and published population series showing no differences. ${ }^{5}$ On the other hand, traditional postoperative mortality (in-hospital mortality and/or 30-day mortality) only partially reflect the true surgical risk, which is best represented by the 90day mortality rate. ${ }^{6}$

The GEVATS project was primarily designed to determine the effect of the eponymous surgery on the 90-day postoperative mortality rate following anatomical lung resection. Its secondary objective was to determine whether VATS influences the long-term oncological prognosis of patients who undergo surgery for lung cancer.

In this paper, we present the current practice of VATS in Spain and our initial results regarding the perioperative course after anatomical lung resection. Moreover, we describe the structure, methodology, and quality systems implemented by the GEVATS as well as the possible implications derived from the selection of patients, regardless of intention, of a voluntary multicentre study.

\section{Methods}

Spanish group of video-assisted thoracic surgery

The GEVATS project of the Spanish Society of Thoracic Surgery (SECT) was founded in May 2015, and all thoracic surgery services of the Spanish National Health System were invited to become members. The research project was approved by the ethics committees of all the participating centres, and informed consent was obtained from the recruited patients to use their clinical data for scientific purposes.

A prospective multicentre cohort study was designed to record all anatomical lung resections performed within each participating department over 15 months (12/20/2016-03/20/2018). The oncological monitoring period ends on 03/20/2022.

Bilateral surgical procedures and those performed on patients younger than 18 years old were excluded.

At the beginning of the study, all the local researchers were informed that every centre would be audited after the recruitment had finished. However, the details of the audit to be undertaken were not intentionally announced.

\section{Database}

The programming language used was PHP, under a Symfony development framework. The information was stored in a MySQL database that included 283 variables structured across the following five blocks: baseline characteristics, staging and pathological diagnosis, surgical procedure, postoperative morbimortality and oncological follow-up. Blocks 2 and 5 were relevant only for patients with lung carcinoma.

All variables were adapted based on the standardisation document of the Society of Thoracic Surgeons (STS) and the ESTS. ${ }^{7}$ Cases of postoperative morbidity included those occurring during the first 30 days or before discharge, and mortality was recorded at 90 days. Complications were classified based on whether they were respiratory, cardiovascular, or other according to the severity guidelines of the Clavien-Dindo classification. ${ }^{8}$

VATS was defined by consensus as the absence of rib spreading, regardless of the number of incisions performed. The interested reader can find online more detailed information about the database variables (supplementary material).

\section{Sample size}

The necessary sample size was calculated based on the primary objective of the study (i.e., to demonstrate differences in the 90-day mortality rate based on the type of surgical approach). As such, an independent proportionality analysis was performed using a chisquare test to estimate a mortality of $4 \%$ for open surgery (control group) and a mortality of $2 \%$ for VATS, with a VATS/open ratio of $1: 3$, an alpha level of 0.05 , a statistical power of 0.8 , and a two-tailed hypothesis test. The resulting sample size was 3238 patients (VATS, $n=804$; open, $n=2434$ ).

\section{Auditing systems}

In addition to the filters in the database itself that served as a quality control during data entry by excluding implausible values and incompatibility between two or more variables, the following monitoring systems were established.

1) Records with missing values regarding the key variables: "type of lung resection", "type of surgical approach", and "patient discharge status" were excluded.

2 ) The recruitment rate of each centre, defined as the percentage of patients registered over all eligible patients $(100 \times$ registered patients/eligible patients), was validated. To accomplish this goal, the local researcher of each department provided the GEVATS coordinator (RE) with an official document issued by the head of the clinical documentation department of the corresponding hospital indicating the number of lobectomies and pneumonectomies performed during the period of interest (20/12/2016-20/03/2018) using the 10th revision of the International Statistical Classification of Diseases and Related Health Problems (ICD-10).

Because this classification system co-codes atypical resections and anatomical segmentectomies, the latter were not specifically monitored. However, since the ICD-10 codes for lobectomy and pneumonectomy consider whether the surgical approach is endoscopic or open, the recruitment rate validation would allow us to obtain official data on the implementation of VATS.

3) Centres that recruited fewer than 15 patients or had recruitment rates lower than $10 \%$ were excluded.

4) For data validation purposes, we considered representative to audit a $20 \%$ sample of patients included by each centre (up to a maximum of 20 patients). This criterion involved the monitoring of 535 patients (i.e., $15.1 \%$ of the entire sample). The variables audited included the "date of surgery", "type of lung resection", "type of surgical approach", "length of postoperative stay", "occurrence of postoperative Grade IIIb-V complications" (respiratory, cardiovascular, or other), and "patient discharge status".

The coordinator and internal scientific committee validated the data. To that end, each local investigator sent their corresponding hospital discharge reports based on a randomised list of recruited patients. Each patient to be audited was identified by the name of the .pdf file of their respective discharge report, which was equivalent to the GEVATS patient code. All other identifying information in the discharge report itself was hidden before being sent to the assigned auditor.

When necessary, the auditor requested additional and necessary clinical reports to certify the validity of the data (e.g., surgical protocol, intensive care unit report, and so on).

The similarity between the data recorded in the GEVATS database and those in the official documents was analysed for each 
department and for each variable audited. Accuracy was expressed as intervals, with an upper accuracy limit $(100 \times$ matching data/verifiable data) and lower accuracy limit $(100 \times$ matching data/all evaluated data).

\section{Statistical analysis}

The descriptive analysis of the data was performed using percentages for the qualitative variables and measures of central tendency (mean or median) and dispersion (standard deviation or 25-75th percentiles) were used for the quantitative variables depending on data distribution. Data normality was evaluated using the Shapiro-Wilk test and visual interpretations of the corresponding histograms.

The correlation between the VATS percentages obtained from the administrative reports and the corresponding percentages recorded in the GEVATS database for each hospital were evaluated using Pearson's correlation coefficient $(r)$ and represented by a scatterplot.

The 33 participating departments were grouped based on their recruitment rate: $<80 \%, 80-94 \%$, or $95-100 \%$. The possible effect of low recruitment on the major postoperative variables (i.e., Grade IIIb-V complications during the first 30 days or before discharge and the 90-day mortality rate) was assessed using unadjusted and adjusted binary logistic regressions for age, sex, type of resection, predictive postoperative forced expiratory volume (FEV1ppo), and type of surgical approach. The results were expressed as odds ratios (ORs) with their respective 95\% confidence intervals (95\% CIs) and significance levels (p), using the group of hospitals with a recruitment rate of $95-100 \%$ as the reference. All data analyses were performed using Stata/MP 14.0.

\section{Results}

The patients recruited and excluded because of the auditing systems are represented in a flowchart (Fig. 1). The number of patients included per hospital ranged from 17 to 264 (mean $=107$, standard deviation $=57.2)$, with a median recruitment rate of 99\% (25-75th percentile interval: $76-100 \%$ ) and an overall recruitment rate of 83.3\% (Fig. 2). Of the 33 departments, 13 reached 100\% recruitment ( 1893 patients; $53.6 \%$ of the sample), six were between $95 \%$ and $99 \%$ (719 patients; $20.4 \%$ ), five were between $80 \%$ and $94 \%$ (440 patients; $12.4 \%$ ), and nine did not reach $80 \%$ recruitment ( 481 patients, $13.6 \%$ ).

The analysis of the recruitment rate and its association with the presence of severe (Grade IIIb-V) postoperative complications and the 90-day mortality rate, using the group of hospitals with a recruitment rate $\geq 95 \%$ as the reference, was not significant. However, the unadjusted regressions revealed that a recruitment rate $<80 \%$ was associated with a tendency to lower postoperative morbidity and 90-day mortality rates (Table 1 ).

The overall percentage of procedures registered as VATS was $54.3 \%$ (1917/3533 patients), with a specific VATS rates for segmentectomy and lobectomy of $65.6 \%$ (156/238 pacientes) and $57.4 \%$ (1755/3059 patients), respectively. The percentages of VATS recorded by each hospital in the GEVATS database were highly correlated with the corresponding percentages based on administrative department reports, $r=0.91$ (Fig. 3 ).

The overall accuracy percentage regarding the data recorded and the data evaluated based on the clinical reports of hospital discharge was excellent, ranging between $97.7 \%$ and $98.5 \%$ (Table 2).

The descriptive analyses of the major baseline, surgical, and postoperative variables, including data quality regarding missing values, are shown in table format (Table 3 ).

\author{
Initial Sample \\ 3581 patients \\ (41 departments )
}

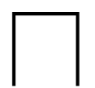

Quality data: preliminary analysis

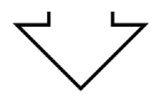

Missing key variables
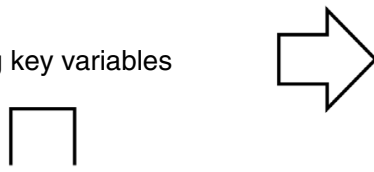

26 patients

Recruitment Audit

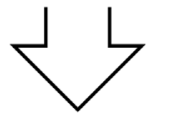

$<15$ patients and/or

recruitment rate $<10 \%$
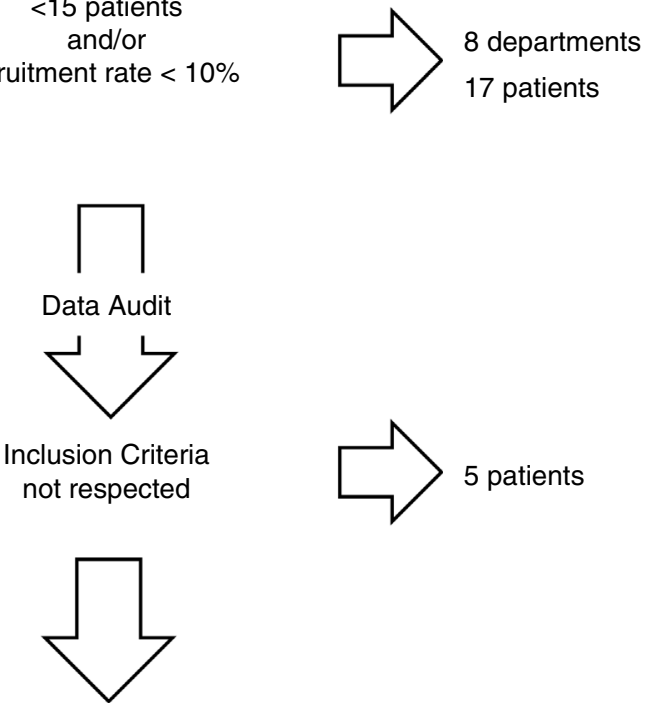

Final Sample 3533 patients (33 departments)

Fig. 1. Audit process. Flow chart representing the number of GEVATS patients and departments regarding the different auditing stages.

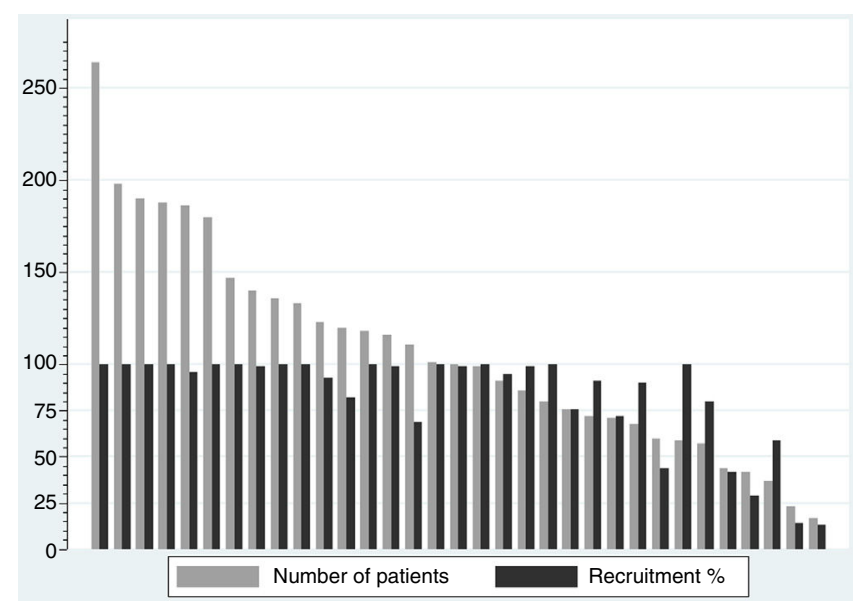

Fig. 2. Recruitment by centre. Number of patients registered per centre and their respective recruitment rates based on the reports of the clinical documentation departments of each hospital. 
Table 1

Risks of major postoperative complications and mortality (30 days or before discharge) and the 90-day mortality based on the recruitment rate (19 departments with a $95-100 \%$ recruitment rate were used as the reference group; $n=2612$ patients).

\begin{tabular}{|c|c|c|c|c|c|c|}
\hline & $\mathrm{OR}^{\mathrm{a}}$ & $p$-Value ${ }^{a}$ & $95 \% \mathrm{CIs}^{\mathrm{a}}$ & $\mathrm{OR}^{\mathrm{b}}$ & $p$ value $^{b}$ & $95 \% \mathrm{CIs}^{\mathrm{b}}$ \\
\hline \multicolumn{7}{|c|}{ Grade IIIb-V Complications } \\
\hline $80-94 \%$ & 1.11 & 0.638 & $1.71-1.76$ & 0.79 & 0.349 & $0.9-1.28$ \\
\hline$<80 \%^{\mathrm{d}}$ & 0.61 & 0.081 & $0.36-1.06$ & 0.71 & 0.235 & $0.40-1.25$ \\
\hline \multicolumn{7}{|c|}{ 90-Day mortality } \\
\hline $80-94 \%{ }^{c}$ & 1.09 & 0.745 & $0.63-1.92$ & 0.69 & 0.219 & $0.39-1.24$ \\
\hline$<80 \%$ & 0.46 & 0.051 & $0.21-1.00$ & 0.56 & 0.157 & $0.26-1.25$ \\
\hline
\end{tabular}

a Unadjusted values.

b Adjusted the following variables: age (quantitative), sex, type of lung resection (segmentectomy, lobectomy-bilobectomy, or pneumonectomy), type of surgical approach (VATS or open surgery), and FEV1ppo (quantitative).

c Group of five departments ( $n=440$ patients) with a recruitment rate between $80 \%$ and $94 \%$

d Group of nine departments ( $n=481$ patients) with a $<80 \%$ recruitment rate.

The interested reader can find online more detailed information about the database descriptive analysis (supplementary material).

\section{Discussion}

The Spanish VATS Group managed to recruit 3533 anatomical lung resections from 33 thoracic surgery departments in fifteen months (December 2016-March 2018). The audit process demonstrated an $83 \%$ overall recruitment rate and a $98 \%$ data accuracy across all departments. In addition, the data registered showed a $54 \%$ VATS rate $(65.6 \%$ for segmentectomy and $57.4 \%$ in case of lobectomy).

Currently, the most commonly accepted quality standards related to the major indicators of the process and outcome of lung resection surgery are derived from the STS and ESTS databases. Recognising the immense potential of these projects to serve as a continuous source of knowledge for our specialty, the representativeness of the US and Europe is challenging. In fact, according to a recent report, the STS database only presented $25 \%$ centre and $38 \%$ patient penetrance by $2013 .^{9}$

On the other hand, the representativeness of administrative databases is overshadowed by their deficiencies regarding the analysis of certain indicators, given the lack of specific clinical variables associated with a particular pathology or procedure. ${ }^{10}$

Spain, a country with a predominant National Health System, has 53 public departments of thoracic surgery. Of these departments, 33 (62\%) are members of the GEVATS project. Regarding the representation of the Spanish territory, 12 out of 17 Autonomous Communities (71\%) and 19 out of 30 (63\%) Provinces with at least one thoracic surgery department are represented in our Group.

According to a report by the Spanish Ministry of Health, 30\% of hospital discharges in 2018 derived from the private health system. However, only $9-10 \%$ of major thoracic surgical procedures (code 120 Diagnosis-Related Group) were performed out of a public institution throughout 2016 to $2017 .{ }^{11}$ Given that the overall recruitment of the GEVATS project was $83 \%$, we could conclude that our sample included, approximately, 50\%of the anatomical lung resections performed in our country during the study period.

Since the Spanish multicentre cooperative group dealing with videothoracoscopy for minor procedures (1573 patients, registered from 1996 to 1998), different nationwide surgical cohort studies and benchmarking projects have been developed in our country. ${ }^{12-16}$

Recently, the results of the Spanish multicentre prospective cohort study of the Group of Postoperative Complications of the Spanish Society of Thoracic Surgeons (GPC-SECT), has published the first known results about VATS implementation in Spain for lung cancer. This study registered 3307 patients operated on for lung cancer in 24 national thoracic surgery departments between June 2012 and November 2014. The percentages of VATS were $30.4 \%$ in men and $34.3 \%$ in women ( $9.3 \%$ of patients in that study underwent wedge resection), which means that the VATS implantation in our country, has nearly doubled after 5 years. ${ }^{17}$

One of the major handicaps of any voluntary database is the potential bias related to selection of patients to be included. In this sense, few studies have attempted to analyse and demonstrate this selection using administrative data or other mandatory population registers as a reference. In addition, studies that have attempted to demonstrate how this selection might influence the results and conclusions of a multicentric, national, and/or continental registry or database are rare. ${ }^{18}$ In our study, although we did not find a significant association between a lower recruitment rate and a lower complication rate, a trend was clearly present in the unadjusted

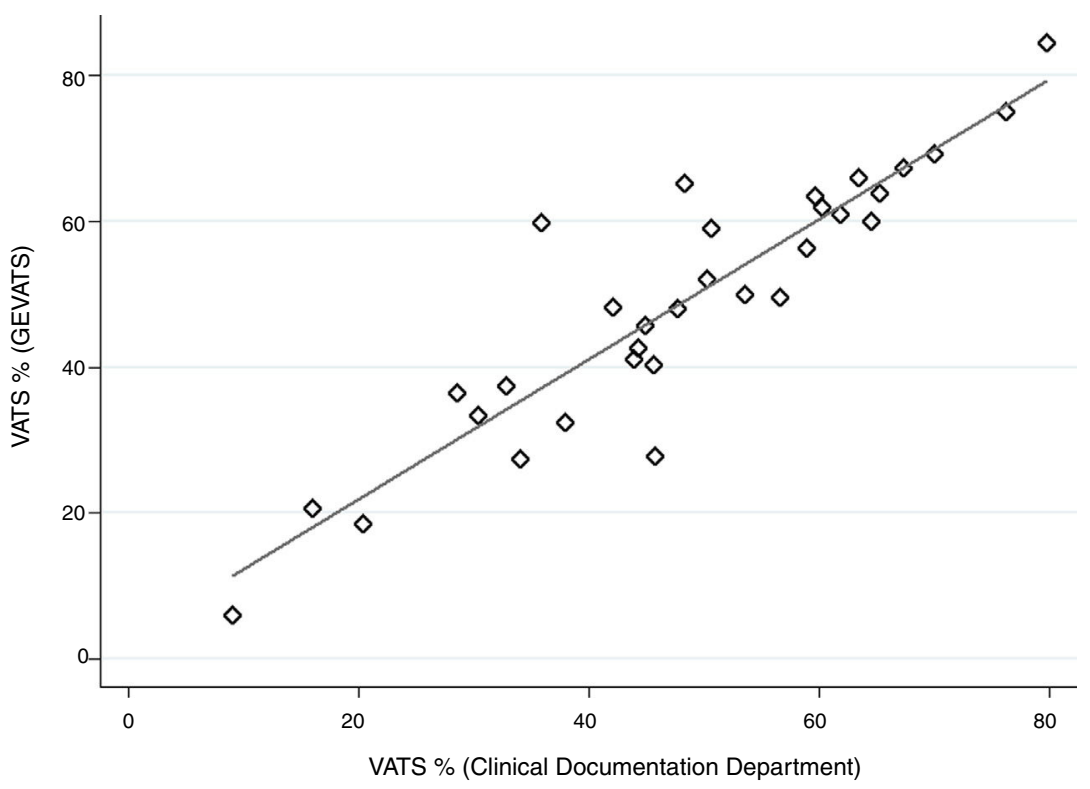

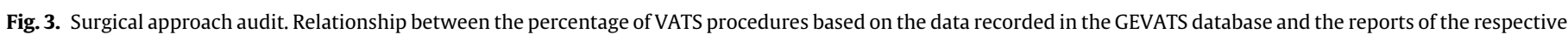
clinical documentation departments; each rhombus corresponds to a GEVATS centre; Pearson's correlation coefficient $(r)$.

Please cite this article in press as: Embun R, et al. Spanish Video-Assisted Thoracic Surgery Group: Method, Auditing, and Initial Results From a National Prospective Cohort of Patients Receiving Anatomical Lung Resections. Arch Bronconeumol. 2020. https://doi.org/10.1016/j.arbres.2020.01.005 
Table 2

Assessment of data accuracy base on six key variables or group of variables.

\begin{tabular}{|c|c|c|c|c|c|c|c|}
\hline Variable & Accurate data & No verifiable data & No accurate data & Valuable data & All data & Upper accuracy rate ${ }^{e}$ & Lower accuracy rate ${ }^{f}$ \\
\hline Surgery date $\mathrm{a}^{\mathrm{a}}$ & 531 & 4 & 0 & 531 & 535 & $100.0 \%$ & $99.3 \%$ \\
\hline Type of surgical approach ${ }^{b}$ & 517 & 11 & 7 & 524 & 535 & $98.7 \%$ & $96.6 \%$ \\
\hline Type of lung resection ${ }^{\mathrm{a}}$ & 525 & 1 & 9 & 534 & 535 & $98.3 \%$ & $98.1 \%$ \\
\hline Grade IIIb-IV complications ${ }^{c}$ & 527 & 2 & 6 & 533 & 535 & $98.9 \%$ & $98.5 \%$ \\
\hline Postoperative stay & 505 & 6 & 24 & 529 & 535 & $95.5 \%$ & $94.4 \%$ \\
\hline Discharge status ${ }^{\mathrm{d}}$ & 532 & 2 & 1 & 533 & 535 & $99.8 \%$ & $99.4 \%$ \\
\hline Total & 3137 & 26 & 47 & 3184 & 3210 & $98.5 \%$ & $97.7 \%$ \\
\hline
\end{tabular}

a Inclusion criteria for GEVATS.

b VATS vs open surgery.

c Based on the assessment of three complication groups (12 respiratory, seven cardiovascular, and seven other) and severity according to the Clavien-Dindo classification.

d Living vs dead.

e (Matching data/verifiable data) $\times 100$.

$\mathrm{f}$ (Matching data/all evaluated data) $\times 100$.

Table 3

Description of the major variables included in the GEVATS

\begin{tabular}{|c|c|c|c|}
\hline & $\begin{array}{l}\text { Statistics or } \\
\text { number }\end{array}$ & Validd \% & Missing \% \\
\hline Type of resection & & & 0 \\
\hline Bi/Lobectomy & 3059 & 86.6 & \\
\hline Segmentectomy & 238 & 6.7 & \\
\hline Pneumonectomy & 236 & 6.7 & \\
\hline VATS approach & 1917 & 54.2 & 0 \\
\hline Type of VATS & & & 0 \\
\hline Biportal & 1232 & 64.3 & \\
\hline Three or more ports & 520 & 27.1 & \\
\hline Uniportal & 165 & 8.6 & \\
\hline Conversion from VATS to Open & 361 & 15.8 & 0 \\
\hline Postoperative stay (median; $25-75$ th) & 5 days (4-7) & & 0.2 \\
\hline In-hospital mortality & & & 0 \\
\hline VATS & 14 & 0.7 & \\
\hline Open & 42 & 2.6 & \\
\hline 90-Day mortality & & & 0.4 \\
\hline VATS & 24 & 1.3 & \\
\hline Open & 79 & 4.9 & \\
\hline
\end{tabular}

analysis. The reasons for participating centres to optimise recruitment were not required but both, the loss of interest in the study and the necessary effort for data entry, could play definitive roles.

The estimates for sample size were only partially successful, since the percentage of VATS registered (54\%) was notably higher than the expected value (25\%). However, the estimated and registered values of 90-day mortality rates for VATS (registered vs estimated $2 \%$ ) and open surgery (registered $4.9 \%$ vs estimated $4 \%$ ) were somehow similar. This way, the recalculated sample size, based on the registered data, would have result in a sample of 718 patients (VATS 389 and Open 329 patients). Therefore, we can conclude that the GEVATS cohort will even allow stratified and propensity score analyses with enough statistical power as to obtain robust conclusions. The opportunity of clinical analyses based only on those centres with a 100\% recruitment rate (1893 patients; $53.6 \%$ of the sample), could be another interesting chance for future projects related to the GEVATS cohort.

Although the validation of recorded data in multicentre registries is gaining popularity over the last years, the proportion of centres and patients audited is consistently low. ${ }^{19-21}$ In this regard, the recruitment rate of all the GEVATS departments and a stratified random sample of our cohort (15\% of patients) were audited, including the most clinically significant variables or those considered as potential sources of conflict of interest. Agreement rate between our registered and official data were consistently high throughout the six key variables audited, in consonance with the results obtain by the STS database audits. ${ }^{22}$
The proportion of missing values is another known quality parameter of a database. ${ }^{23}$ Regarding the 242 variables comprising the four blocks analysed (baseline characteristics, diagnosis and staging, surgery, and postoperative period), the percentage of missing values was $0.95 \%$. This value is excellent in terms of completion and perhaps the result of the design and filters implemented in the database, both of which were key during data entry.

Regarding our clinical results, the VATS lobectomy rate of $57.4 \%$ is worth mentioning because it is more consistent with the data published by the major North American databases than with the results derived from the European registry. ${ }^{2,3,24}$ Rates in excess of $50 \%$ in Europe have been published by the Dutch National Registry of Lung Surgery. ${ }^{25}$ Our in-hospital mortality rate (1.6\%) and 90 day mortality rate $(2.9 \%)$ are in line with or even lower than those published in other national studies. ${ }^{26}$

\section{Limitations}

Given the voluntary nature of GEVATS and its manifest interest in minimally invasive surgery, one of our major limitations is related to the representativeness of the practice of VATS in Spain. Although $90 \%$ of the thoracic surgery departments in Spain have some degree of experience in performing anatomical lung resections via VATS (national survey, 2015), the actual figures might differ from those reported in this study. ${ }^{4}$

On the other hand, the auditing systems, excluding the reports issued by the departments of clinical documentation, were implemented by some of the member thoracic surgeons of GEVATS (the coordinator and the internal scientific committee) and not by a professional external auditing service, which might have influenced the reliability of our results. However, because one of the criteria to be audited was the degree of severity of postoperative complications, we emphasise the importance of the experience of the clinical professional in this regard.

\section{Conclusions}

The GEVATS cohort represents, to date, the most ambitious prospective study of the Spanish thoracic surgery, regarding the number of centres involved, the total sample size, and the auditing systems implemented. Our results suggest that VATS is widely implemented in Spain.

Although our series did not demonstrate a significant association (only a trend between lower postoperative complications and lower recruitment rates), we believe that this parameter and its possible implications should deserve further attention by the main ongoing and future voluntary registries and multicentre studies of surgical series. 
Last, the significant representativeness and excellent quality of our data will allow us to obtain highly reliable results in future projects, in which the effect of the surgical technique will be one of our primary foci.

\section{Funding statement}

All costs related to the start-up and maintenance of the GEVATS database were covered by Ethicon, Johnson \& Johnson. The authors had freedom of investigation and full control of the design of the study, methods used, outcome parameters and results, data analysis, and production of the written report.

The GEVATS was awarded a grant from the Spanish Society of Thoracic Surgery as the best national research project of 2015.

\section{Conflict of interest}

The authors declare no conflict of interest.

\section{Acknowledgements}

We thank Johnson \& Johnson for their collaboration in the development of the Spanish VATS Group. We also thank all those responsible for the clinical documentation services of each hospital for actively participating in the audit of our study.

\section{Appendix A. Supplementary data}

Supplementary data associated with this article can be found, in the online version, at doi:10.1016/j.arbres.2020.01.005.

\section{References}

1. Magee MJ. Database audit in thoracic surgery. Thorac Surg Clin. 2017;27:291-6.

2. Mehta H, Osasona A, Shan Y, Goodwin JS, Okereke IC. Trends and outcomes of thoracoscopic lobectomy or segmentectomy: a national surgical quality improvement project analysis. Semin Thorac Cardiovasc Surg. 2018;30:350-9.

3. Seder CW, Salati M, Kozower BD, Wright CD, Falcoz PE, Brunelli A, et al. Variation in pulmonary resection practices between the society of thoracic surgeons and the European society of thoracic surgeons general thoracic surgery databases. Ann Thorac Surg. 2016;101:2077-84.

4. Embun R, Martínez Hernández N, Call S, de Olaiz Navarro B, Zabaleta J, Ramos R, et al. Video-assisted thoracic surgery and anatomical lung resections Where do we stand? National survey by the Spanish Society of Thoracic Surgery. Cir Esp. 2017;95:24-9.

5. Paul S, Sedrakyan A, Chiub Y, lin, Nasar A, Port JL, et al. Outcomes after lobectomy using thoracoscopy vs thoracotomy: a comparative effectiveness analysis utilizing the Nationwide Inpatient Sample database. Eur J Cardiothorac Surg. 2013;43:813-7.

6. Pezzi CM, Mallin K, Mendez S, Gay EG, Putnam JB. Ninety-day mortality after resection for lung cancer is nearly double 30-day mortality. J Thorac Cardiovasc Surg. 2014;148:2269-78.
7. Fernandez FG, Falcoz PE, Kozower BD, Salati M, Wright CD, Brunelli A. The Society of Thoracic Surgeons and the European Society of Thoracic Surgeons general thoracic surgery databases: joint standardization of variable definitions and terminology. Ann Thorac Surg. 2015;99:368-76.

8. Dindo D, Demartines N, Clavien PA. Classification of surgical complications: a new proposal with evaluation in a cohort of 6336 patients and results of a survey. Ann Surg. 2004;240:205-13.

9. Tong BC, Kim S, Kosinski A, Onaitis MW, Boffa DJ, Habib RH, et al. Penetration completeness, and representativeness of the society of thoracic surgeons general thoracic surgery database for lobectomy. Ann Thorac Surg. 2019;107:897-902.

10. Shahian DM, Silverstein T, Lovett AF, Wolf RE, Normand SLT. Comparison of clinical and administrative data sources for hospital coronary artery bypass graft surgery report cards. Circulation. 2007;115:1518-27.

11. https://www.mscbs.gob.es/[Internet]. Spain: Ministerio de Sanidad, Consumo y Bienestar Social. Sanidad en datos. Available from: https://www.mscbs.gob.es/estadEstudios/sanidadDatos [cited 19.12.19].

12. Freixinet J, Varela G, Rodríguez P, Embún R, Rivas JJ, De la Torre M, et al. Benchmarking en cirugía torácica. Tercera edición. Arch Bronconeumol. 2016;52:204-10.

13. Rivas de Andrés JJ, Freixinet Gilart J, Rodríguez de Castro F. Estudio multicéntrico español de cirugía videotoracoscópica. Arch Bronconeumol. 2002;38:60-3.

14. Duque JL, Rami-Porta R, Almaraz A, Castanedo M, Freixinet J, Fernández de Rota A. Risk factors in bronchogenic carcinoma surgery. Arch Bronconeumol. 2007:43:143-9.

15. Embun R, Rivas De Andrés J, Call S, De Olaiz Navarro B, Freixinet JL, Bolufer S, et al. Causal model of survival after pulmonary metastasectomy of colorectal cancer: a nationwide prospective registry. Ann Thorac Surg. 2016;101:1883-90.

16. García-Yuste M, Matilla JM, Cañizares MA, Molins L, Guijarro R. EMETNESEPAR. Surgical treatment of low and intermediate grade lung net. J Thorac Dis. 2017;9:S1435-41.

17. Fibla JJ, Molins L, Quero F, Izquierdo JM, Sánchez D, Hernández J, et al. Perioperative outcome of lung cancer surgery in women: results from a Spanish nationwide prospective cohort study. J Thorac Dis. 2019;11:1475-84.

18. Rich AL, Tata LJ, Stanley RA, Free CM, Peake MD, Baldwin DR, et al. Lung cancer in England: information from the national lung cancer audit (LUCADA). Lung Cancer. 2011;72:16-22.

19. Magee MJ, Wright CD, McDonald D, Fernandez FG, Kozower BD. External validation of the Society of Thoracic Surgeons General thoracic surgery database. Ann Thorac Surg. 2013;96:1734-9.

20. Brunelli A, Falcoz PE. European institutional accreditation of general thoracic surgery. J Thorac Dis. 2014;6:284-7.

21. Endo S, Ikeda N, Kondo T, Nakajima J, Kondo H. Development of an annually updated Japanese national clinical database for chest surgery in 2014. Gen Thorac Cardiovasc Surg. 2016;64:569-76.

22. Seder CW, Magee MJ, Broderick SR, Brown LM, Blasberg JD, Kozower BD, et al. The society of thoracic surgeons general thoracic surgery database 2019 update on outcomes and quality. Ann Thorac Surg. 2019:107.

23. Salati M, Brunelli A, Dahan M, Rocco G, Van Raemdonck DEM, Varela G. Taskindependent metrics to assess the data quality of medical registries using the European Society of Thoracic Surgeons (ESTS) Database. Eur J Cardiothorac Surg. 2011;40:91-8.

24. Salati M, Brunelli A, Decaluwe H, Szanto Z, Dahan M, Varela G, et al. Report from the European Society of Thoracic Surgeons Database 2017: patterns of care and perioperative outcomes of surgery for malignant lung neoplasm. Eur J Cardiothorac Surg. 2017:52:1041-8.

25. ten Berge M, Beck N, Heineman DJ, Damhuis R, Steup WH, van Huijstee PJ, et al. Dutch lung surgery audit: a national audit comprising lung and thoracic surgery patients. Ann Thorac Surg. 2018;106:390-7.

26. Falcoz P, Puyraveau M, Rivera C, Bernard A, Massard G, Mauny F, et al. The impact of hospital and surgeon volume on the 30-day mortality of lung cancer surgery: a nation-based reappraisal. J Thorac Cardiovasc Surg. 2010;148:841-8. 